\title{
Satisfaction and expressed needs of pharmaceutical care services and challenges recognized by patients in South Korea
}

This article was published in the following Dove Press journal:

Patient Preference and Adherence

II August 2017

Number of times this article has been viewed

\author{
JiEun Kang, ${ }^{1,2, *}$ Kiyon \\ Rhew, ${ }^{3, *}$ Jung Mi Oh, ${ }^{4}$ \\ NaYoung Han, ${ }^{4}$ lyn-Hyang \\ Lee, ${ }^{5}$ Nam Kyung Je, ${ }^{6}$ \\ Eunhee $\mathrm{Ji},{ }^{7}$ Euni Lee, ${ }^{4}$ \\ Jeong-Hyun Yoon, ${ }^{6}$ \\ Sandy Jeong Rhie'
}

'Division of Life and Pharmaceutical Sciences Graduate School, Ewha Womans University, Seoul, Republic of Korea; ${ }^{2}$ Department of Pharmacy, National Medical Center, Seoul, Republic of Korea; ${ }^{3}$ College of Pharmacy, Dongduk Women's University, Seoul, Republic of Korea; ${ }^{4}$ College of Pharmacy, Seoul Nationa University, Seoul, Republic of Korea; ${ }^{5}$ College of Pharmacy, Yeungnam University, Gyeongbuk, Republic of Korea; ${ }^{6}$ College of Pharmacy, Pusan National University, Busan, Republic of Korea; ${ }^{7}$ College of Pharmacy, Gachon University, Incheon, Republic of Korea

*These authors contributed equally to this work

Correspondence: Sandy Jeong Rhie Division of Life and Pharmaceutical Sciences Graduate School and College of Pharmacy, Ewha Womans University, 52 Ewhayeodae-gil, Seodaemun-gu, Seoul 03760, Republic of Korea

Tel +82 I0 337। 3882

Fax +82 23277285 I

Email sandy.rhie@ewha.ac.kr

Jeong-Hyun Yoon

College of Pharmacy, Pusan National University, 2 Busandaehak-ro,

63 beon-gil, Geumjeong-gu,

Busan 4624I, Republic of Korea

Tel +82 I0 55343775

Fax +82 5I 5136754

Email jyoon@pusan.ac.kr
Purpose: To assess the degree of satisfaction and expressed needs of pharmaceutical care services in patients with chronic diseases and explore the factors related to the needs from patients' perspectives for the further development of pharmaceutical care service models.

Patients and methods: A cross-sectional survey of 220 patients (mean age \pm SD: $61.3 \pm 13.1$, male:female: 104:116) was conducted. The questionnaire was structured to measure patients' degree of satisfaction and expressed needs using a 5-point Likert scale. Additionally, preferred duration, methods of service delivery, and willingness to pay were surveyed. Responses were analyzed using an ordinal regression method to predict factors that were related to pharmaceutical care services.

Results: Sixty-seven patients had experienced pharmaceutical care services. Their satisfaction levels were high in all categories; however, there were no significant differences between categories. The levels of expressed needs were similar among categories without significant differences. The preferred delivery method was a face-to-face conversation combined with being provided with written information (53.2\%). The preferred duration was $\leq 10 \min (70.5 \%)$. About $48 \%$ of the patients showed willingness to pay for the service. Education level and region influenced patients' needs.

Conclusion: The satisfaction and needs of pharmaceutical care services was very positive; however, noticing only a third of patients experienced pharmaceutical care services, this may indicate a lack of awareness and less appreciation of pharmacists by patients. Details concerning patients' awareness and the value of pharmaceutical care services require further investigation.

Keywords: pharmaceutical care service, satisfaction, needs, patient perspective

\section{Introduction}

Globally, human life expectancy is increasing at a rate of more than 3 years every 10 years, and there is a 5-year life expectancy increase from 2000 to $2015 .^{1}$ In 2011, the healthy life expectancy of Koreans was 70.7 years. Unfortunately, it was found to be approximately 10 years shorter than the life expectancy at birth of 81.2 years. Koreans have been suffering from diseases for 10 years before their deaths. This was predicted to be due to chronic metabolic diseases and a need for a comprehensive management program. ${ }^{2}$ In 2015, the cause of death in Korea was 150.8 cases of malignant tumors, 55.6 cases of heart diseases, 48.0 cases of cerebral vascular diseases, 28.9 cases of pneumonia, 20.7 cases of diabetes, and 9.9 cases of hypertensive diseases based on a population of 100,000 . The increase in chronic metabolic diseases continues and the socioeconomic burden for the treatment of these diseases is increasing. ${ }^{3}$ 
Unfortunately, this is also aligned with an increase in prescriptions, limited accessibility to health care professionals, unreliable operations and regulations, and health care costs. "Change" is the new normal for our health care environment. The health care system has shifted from episodic care to population health management and from volume- to valuebased care. Efforts that deliver effective and equitable global health care are needed.

To confront the increasing burden of chronic disease management, effective and well-designed pharmaceutical care services (PCSs) require implementation. ${ }^{4-10}$ The role of pharmacists and their contribution have been emphasized in treating chronic metabolic diseases and preventing subsequent complications. ${ }^{4-10}$ There are many studies that measure the outcomes of PCSs globally; however, the results are not consistent. ${ }^{5,11,12}$ They may vary depending on the target patient population, the service setting, and even the questionnaires' content. As pharmacists look for opportunities to develop and expand the scope of practice for PCSs, patients' views on these issues must be understood. Patients' demands for access to services will promote the initiatives of PCSs and accelerate the changes of successful PCSs' implementation.

In South Korea, since the development of PCSs is at the beginning stages, patients' degree of satisfaction in PCSs and how they should be developed requires analysis. Few studies have addressed patients' satisfaction with pharmacy services in South Korea. Most studies were conducted with general patients at community pharmacies, and the results were contradictory. ${ }^{13,14}$

According to a review of literature, 20 out of 33 studies on the subject of pharmacy services in South Korea were about prescription dispensing services, three for PCS research, and two for health promotion services. It confirmed that the pharmacy's reliance on prescription drugs was high, and at the same time, it showed PCSs and health promotion services had not yet been settled. On the other hand, the most studied subject of the pharmacy service was related to medication instruction, which showed that the most important and importantly recognized service in Korea is medication guidance. ${ }^{15}$ There are several examples of PCSs that are in the beginning stage. The Seoul city's pharmacy association has started the SAFE pharmacy program as a model of the future pharmacy in 2013, and currently more than 200 pharmacies are selected as SAFE pharmacies. SAFE pharmacies have the purpose of making patients safe and healthy by managing their medical history, preventing suicide, and promoting smoking cessation. ${ }^{16,17}$ The activities of the SMART pharmacy in Busan focus on providing "S" afe drug information, "M"anagement of personal health care, "A"ccurate disease information, "R"eliable, trustworthy pharmacy, " $\mathrm{T}$ ”eaching for prevention and management of cardiovascular diseases, but no clinical outcomes have been published yet. ${ }^{18}$

On one side, the major barriers to internationally recognized Good Pharmacy Practice (GPP) standards compliance in community pharmacies in Korea were lack of time and labor, lack of updated clinical information, negative feedback or refusals from prescribers. There were significant differences according to the number of pharmacists and acceptability of the proposed GPP standards. Among these obstacles, the shortage of pharmacists issue cannot be resolved without changes in the pharmacy management environment, as pharmacists should be able to secure the manpower to spend more time on business processes. ${ }^{19}$

Elucidating health care consumers' needs is the primary step to the successful implementation of PCSs. Therefore, we conducted a cross-sectional survey of patients with chronic metabolic diseases to investigate their perceptions of PCSs by questioning their satisfaction and expressed needs. Further, we assessed patients' characteristics related to the expressed PCSs needs.

This study was approved by the Institutional Review Board of Seoul National University (IRB number 1401/ 001-013). Written consent was obtained from respondents prior to participation. This study was conducted in accordance with the Declaration of Helsinki.

\section{Material and methods}

\section{Selecting target diseases and stakeholders for PCSs}

Analytic Hierarchy Process was conducted to select target diseases which we intended to use to develop the PCS model. ${ }^{20}$ In this process, the seven chronic metabolic diseases were selected from eleven which indicated as being most likely to place a high demand on PCSs by both the Ministry of Health \& Welfare of South Korea and the Korean National Health \& Nutrition Examination Survey (in press). In addition, through stakeholder mapping techniques, we found the main consumers of PCSs should be health care providers, pharmacists, and patients. We previously published the qualitative analyses of the PCS needs by health care providers and this study focused on PCSs with patients' perspectives. ${ }^{21}$

\section{Developing survey questionnaire}

We aimed to investigate current knowledge, attitude, and practice of PCSs perceived by patients through this 
qualitative survey. A questionnaire was preformulated by facts clustering, opportunity web, and mind map processes so that various matrices of PCSs could be completed. ${ }^{21}$ The prototype questionnaire had consisted of eleven satisfaction and eleven expressed needs. We held focus group discussions with clinical pharmacists with PCSs experiences and pharmacy school faculties, and conducted focused individual interviews with physician specialists and registered nurses. A pretest was performed on seven laymen. The experts and the pretest participants were asked to provide feedback on any aspects - whether the questionnaire covered the full range of subjects to be investigated and whether the details were appropriate. We modified the survey including style, length, and difficulty on completing and attached supplementary pictures to improve understanding. The items that did not achieve content validity index of $80 \%$ were deleted. Through these modifications, seven satisfaction and six needs questions were finalized. Factor analysis was performed on PCSs needs and nearly all items were ranging from 0.64 to 0.78 . The internal consistency reliability with Cronbach's $\alpha$ for the six questions about PCSs needs was 0.81 .

The survey questionnaire consisted of three parts. Part 1 measured patients' satisfaction levels on seven detailed service items: "medication reconciliation", "duplication or interactions", "inpatient drug use review", "medication changes", "storage and instructions to use", "lifestyle modification", and "adherence". Satisfaction was measured only in patients who indicated previously receiving each service. Part 2 measured patients' expressed needs on six items: "medication reconciliation", "medication changes", "patientcustomized services", "drug and health information", "overthe-counter (OTC) drugs and supplements", and "adherence tools". Part 3 measured preferred duration, delivery methods of PCSs, and willingness to pay the fee for PCSs. Each question in Parts 1 and 2 was measured using a 5-point Likert scale: " $1 "=$ least agree to " $5 "=$ most agree. Part 3 consisted of multiple-choice questions (Table 1).

\section{Study setting and survey interview}

The survey was conducted between March and May 2014. Inclusion criteria comprised patients who had chronic diseases and three or more hospital visits within the past year. Patients were excluded if they had health professionals in their family, were not taking any medications, or if they had a medical condition that limited their ability to recall or provide information on the survey. The survey was performed in four different regions of South Korea: Seoul, Gyeonggido located in the northwestern area, Busan located in the southern area, and Gyeongsang-do located in the southeastern area.

Table I Survey questionnaire structures

\begin{tabular}{|c|c|}
\hline Part I & Satisfaction $^{a}$ \\
\hline I. Medication reconciliation & To reconcile current and previous medications \\
\hline 2. Duplications or interactions & To assess duplications and potential drug interactions \\
\hline 3. Inpatient drug use review & To assess appropriateness of drug use during hospitalization \\
\hline 4. Medication changes & To assess and counsel regarding new medications and the reason for the changes \\
\hline 5. Storage and instructions to use & To counsel how to use and store the medication (including self-injections such as insulin, erythropoietin, etc.) \\
\hline 6. Lifestyle modification & To assess and recommend the use of dietary supplements, vitamins, diet, and exercise \\
\hline 7. Adherence & To encourage adherence using special tools, logs, devices, booklets, and brochures \\
\hline Part 2 & Expressed needs ${ }^{b}$ \\
\hline I. Medication reconciliation & To reconcile current and previous medications \\
\hline 2. Medication changes & $\begin{array}{l}\text { To assess and counsel regarding new medications } \\
\text { (including the reason for changes and what to do in case of emergency or adverse events, if applicable) }\end{array}$ \\
\hline 3. Patient-customized services & To provide patient-centered information and care \\
\hline 4. Drug and health information & To provide information on medications, disease prognosis, and general wellness \\
\hline 5. OTC drugs and supplements & To recommend OTC medications, vitamins, or herbal medicine \\
\hline 6. Adherence & $\begin{array}{l}\text { To recommend and instruct how to use tools to improve compliance (ie, set an alarm, medication } \\
\text { logs/brochures, and notification for a refill) } \\
\text { To remind of follow-up visit }\end{array}$ \\
\hline Part 3 & Duration, delivery method, and the willingness to pay \\
\hline I. Duration & To assess preferred duration of the service \\
\hline 2. Initial delivery method & To assess preferred methods of the service provision at the first visit \\
\hline 3. Continuing delivery method & To assess preferred methods of the service provision from the second visit \\
\hline 4. Willingness to pay & To assess patient's intention to pay for the service \\
\hline
\end{tabular}

Notes: aSatisfaction was measured among patients who had experienced PCS. 'Expressed needs were measured in patients regardless of PCS experiences. Abbreviations: OTC, over-the-counter; PCS, pharmaceutical care service. 
Pharmacies were selected according to location and size, which would be important factors when patients choose a pharmacy. They were medium to large sized with 4-7 staff and near the hospital entrance. The target group of patients had regular visits to the pharmacies to fill prescriptions. The surveys were administered after informed, written consent was obtained. Each survey took approximately 20-30 minutes. An interviewer assisted the patient to respond to each question from the beginning to the end of the questionnaire $1: 1$ to assist with readability and completion rate. The interviewers were trained prior to the survey implementation to minimize interinterviewer variability and maximize the collection of responses. The main content of the training was communication techniques with patients and medication therapies for chronic diseases.

\section{Statistical analysis}

We collected and organized the questionnaire data with MS Excel 2016 (Microsoft Corporation, Redmond, WA, USA). SPSS version 23 (IBM Corporation, Armonk, NY, USA) was utilized to analyze the data. Univariate analyses were conducted to describe patients' baseline characteristics. Descriptive statistics were calculated to present the frequencies of the survey responses. Statistical differences of each degree of both satisfaction and needs for the PCSs were tested using an analysis of variance. An ordinal logistic regression was used as the dependent variable to determine the unadjusted ORs and calculate the factors that predicted patients' needs. We considered $P$-values less than 0.05 as statistically significant.

\section{Results}

\section{Participants' demographics}

Participants' characteristics are shown in Table 2. A total of 220 patients (mean age: $61.3 \pm 13.1$ years old, male: $47.3 \%$ ) completed the survey questionnaire. One hundred and twenty-six patients $(57.2 \%)$ had $\geq 2$ chronic diseases, and 85 patients (38.6\%) were taking $\geq 6$ medications per day.

\section{Satisfaction with PCSs}

Participants' satisfaction with PCSs is described in Table 3. Only $30.5 \%$ ( $n=67$ of 220$)$ of patients received at least one PCS. Among 67, the patients received a lifestyle modification service and medication changes service $(n=35)$ which had the most number of responses, and the least number of response was $6.6 \%(n=11)$ of an adherence service. There was a significant difference among the numbers of responses
Table 2 Patients' baseline characteristics $(n=220)$

\begin{tabular}{|c|c|c|}
\hline Characteristics & $\begin{array}{l}\text { Number of } \\
\text { patients }\end{array}$ & $\%$ \\
\hline \multicolumn{3}{|l|}{ Gender } \\
\hline Male:female & $104: 116$ & 47.3:53.7 \\
\hline \multicolumn{3}{|l|}{ Age (mean years $\pm S D)$} \\
\hline \multicolumn{3}{|l|}{$61.3 \pm 13.1$} \\
\hline$\geq 65$ & 123 & 55.9 \\
\hline$<65$ & 97 & 44.1 \\
\hline \multicolumn{3}{|l|}{ Education } \\
\hline College and higher & 81 & 36.8 \\
\hline High school graduate & 65 & 29.6 \\
\hline Middle school graduate or less & 72 & 32.7 \\
\hline No response & 2 & 0.9 \\
\hline \multicolumn{3}{|l|}{ Number of chronic diseases } \\
\hline 1 & 82 & 37.3 \\
\hline 2 & 76 & 34.5 \\
\hline 3 or more & 50 & 22.7 \\
\hline No response & 12 & 5.5 \\
\hline \multicolumn{3}{|l|}{ Number of medications per day } \\
\hline $1-2$ & 62 & 28.2 \\
\hline $3-5$ & 72 & 32.7 \\
\hline $6-9$ & 44 & 20.0 \\
\hline$\geq 10$ & 41 & 18.6 \\
\hline No response & 1 & 0.5 \\
\hline \multicolumn{3}{|l|}{ Location of service } \\
\hline Seoul and its vicinity & 140 & 63.6 \\
\hline Local area & 80 & 36.4 \\
\hline \multicolumn{3}{|l|}{ Residing with family } \\
\hline Yes & 196 & 89.1 \\
\hline No & 22 & 10.0 \\
\hline No response & 2 & 0.9 \\
\hline \multicolumn{3}{|l|}{ Admission } \\
\hline Never hospitalized & 158 & 71.8 \\
\hline$<$ I week & 30 & 13.6 \\
\hline$\geq \mathrm{I}$ week and $<\mathrm{I}$ month & 22 & 10.0 \\
\hline$\geq 1$ month and $<3$ months & 5 & 2.3 \\
\hline$\geq 3$ months & 4 & 1.8 \\
\hline No response & 1 & 0.5 \\
\hline
\end{tabular}

Table 3 Satisfaction with the pharmaceutical care services ${ }^{\mathrm{a}}$

\begin{tabular}{lll}
\hline Items & $\begin{array}{l}\text { Number of } \\
\text { responses }^{b}\end{array}$ & $\begin{array}{l}\text { Degree of satisfaction } \\
\text { (mean } \pm \text { SD) }\end{array}$ \\
\hline Lifestyle modification & 35 & $4.18 \pm 0.91$ \\
Medication reconciliation & 30 & $4.00 \pm 1.04$ \\
Medication changes & 35 & $4.09 \pm 0.97$ \\
Duplications or interactions & 24 & $4.19 \pm 0.78$ \\
Inpatient drug use review & 16 & $4.37 \pm 0.99$ \\
Storage and instructions to use & 15 & $4.16 \pm 0.99$ \\
Adherence & 11 & $4.15 \pm 1.03$
\end{tabular}

Notes: aSatisfaction was measured for 67 patients (30.5\%) who had experienced PCS. 'Multiple selections were allowed and received total 166 responses. $P<0.001$ among items by Pearson's chi-square test. 'Degree of satisfaction was measured using 5-point Likert scale and no significances among items were found.

Abbreviation: PCS, pharmaceutical care service. 
Table 4 Expressed needs for pharmaceutical care services ${ }^{\mathrm{a}}$

\begin{tabular}{ll}
\hline Items & $\begin{array}{l}\text { Degree of expressed needs } \\
(\mathbf{m e a n} \pm \mathbf{S D})^{\mathrm{b}}\end{array}$ \\
\hline Medication changes & $4.17 \pm I .05$ \\
OTC drugs and supplements & $4.11 \pm 1.19$ \\
Patient-customized services & $4.04 \pm 1.06$ \\
Drug and health information & $3.94 \pm 1.21$ \\
Medication reconciliation & $3.85 \pm 1.21$ \\
Adherence & $3.52 \pm 1.37$ \\
\hline
\end{tabular}

Notes: ${ }^{a}$ Expressed needs were measured for 218 patients and two patients did not respond. 'Multiple selections were allowed and measured using 5-point Likert scale. Abbreviation: OTC, over-the-counter.

$(P<0.001)$; however, no significant differences in the degree of satisfaction among PCSs items were observed.

\section{Expressed needs for PCSs}

Participants' expressed needs are shown in Table 4. There were no significant differences in the degree of expressed needs among each PCSs item.

\section{Duration of provision, method of delivery, and willingness to pay for PCSs}

Participants' wishes concerning duration, delivery methods, and willingness to pay for PCSs are shown in Table 5 . The preferred duration of PCSs was $\leq 10 \min (n=155,70.5 \%)$. The preferred delivery method was oral counseling with giving out written information at the first encounter $(n=117$, $53.2 \%)$. Approximately $48 \%$ of patients $(n=106)$ showed willingness to pay for PCSs, and $21.3 \%(n=47)$ responded "undecided".

\section{Factors related to the expressed needs of PCSs}

\section{Medication reconciliation service}

"Medication reconciliation" service was significantly associated with high school graduates (OR 1.87; 95\% CI 1.01-3.46) when compared to the middle school graduates or less. A similar result was observed with patients who received the service in Seoul and its vicinity (OR 2.36; 95\% CI 1.42-3.92) compared to those who received the service in local areas. Moreover, patients who took 3-5 medications demanded the service approximately 2.8 times more compared to those who took 1-2 medications (Table 6).

\section{Medication changes}

"Medication changes" service had a significant association with age ( $\geq 65$ years old, OR $0.57 ; 95 \%$ CI $0.35-0.95$ ),
Table 5 Preferred delivery methods for pharmaceutical care services $(n=220)$

\begin{tabular}{lll}
\hline Items & $\begin{array}{l}\text { Number of } \\
\text { patients }\end{array}$ & $\%$ \\
\hline Duration & & \\
$\leq 10 \mathrm{~min}$ & 155 & 70.5 \\
II-20 min & 32 & 14.5 \\
$21-30 \mathrm{~min}$ & 7 & 3.2 \\
$>30 \mathrm{~min}$ & 18 & 8.2 \\
No need & 8 & 3.6 \\
Delivery method of initial PCSs & & \\
Oral + written instructions & 117 & 53.2 \\
Oral counseling & 82 & 37.3 \\
Written instructions & 14 & 6.3 \\
No need & 7 & 3.2 \\
Delivery method of continuing PCSs & & \\
Direct counseling & 127 & 57.7 \\
Phone & 49 & 22.3 \\
Letter or email & 6 & 2.7 \\
Social network services & 10 & 4.6 \\
Others & 8 & 3.6 \\
No need & 12 & 5.5 \\
No response & 8 & 3.6 \\
Willingness to pay & & \\
Yes & 106 & 48.2 \\
No & 67 & 30.5 \\
Undecided & 47 & 21.3 \\
\hline Ab & &
\end{tabular}

Abbreviation: PCSs, pharmaceutical care services.

education (high school graduates, OR $1.93 ; 95 \%$ CI 1.02-3.63, college graduate or higher, OR 2.17 ; $95 \%$ CI 1.19-3.99), location (Seoul and its vicinity, OR 2.20; $95 \%$ CI 1.31-3.70), and the number of chronic diseases (two chronic diseases, OR $0.34 ; 95 \%$ CI $0.18-0.63$; $\geq 3$ chronic diseases, OR 0.48 ; $95 \%$ CI $0.24-0.94$ ) when compared to each reference (Table 7).

Table 6 Ordinal logistic regression of patient needs for "medication reconciliation" service

\begin{tabular}{ll}
\hline Patients' characteristics & $\begin{array}{l}\text { Unadjusted } \\
\text { OR }(95 \% \mathbf{C I})\end{array}$ \\
\hline $\begin{array}{l}\text { Education } \\
\text { College graduate or more }\end{array}$ & $\mathrm{I} .40(0.78-2.49)$ \\
$\quad$ High school graduate & $\mathrm{I} .87(\mathrm{I} .0 \mathrm{I}-3.46)$ \\
$\quad$ Middle school graduate or less (reference) & \\
Location of services & \\
$\quad$ Seoul and its vicinity & $2.36(\mathrm{I} .42-3.92)$ \\
Local (reference) & \\
Number of medications per day & \\
$\geq 10$ & $\mathrm{I} .69(0.82-3.46)$ \\
$6-9$ & $\mathrm{I} .73(0.85-3.50)$ \\
$3-5$ & $2.82(\mathrm{I} .49-5.32)$ \\
I-2 (reference) & \\
\hline
\end{tabular}


Table 7 Ordinal logistic regression of patient needs for "medication changes" service

\begin{tabular}{ll}
\hline Patient characteristics & $\begin{array}{l}\text { Unadjusted } \\
\text { OR }(95 \% \mathbf{C I})\end{array}$ \\
\hline $\begin{array}{l}\text { Age, years } \\
\quad \geq 65\end{array}$ & $0.57(0.35-0.95)$ \\
$\quad<65$ (reference) & \\
Education & $2.17(1.19-3.99)$ \\
$\quad$ College graduate or higher & $1.93(1.02-3.63)$ \\
$\quad$ High school graduate & \\
$\quad$ Middle school graduate or less (reference) & \\
Location of services & \\
$\quad$ Seoul and its vicinity & $2.20(1.31-3.70)$ \\
$\quad$ Local (reference) & \\
Number of chronic diseases & \\
$\geq 3$ & $0.48(0.24-0.94)$ \\
2 & $0.34(0.18-0.63)$ \\
\hline ( reference) & \\
\hline
\end{tabular}

\section{OTC drugs and supplements service}

"OTC drugs and supplements" service showed a significant inverse association with age ( $\geq 65$ years old, OR 0.59 ; 95\% CI 0.36-0.98) and more than two chronic diseases (OR 0.55; 95\% CI 0.30-0.99). Patients who had an education level of college or higher (OR 1.84; 95\% CI 1.01-3.36) and who received the services in Seoul and its vicinity (OR 1.94; 95\% CI 1.15-3.26) demanded significantly more services compared to patients in the reference groups (Table 8).

\section{Discussion}

Despite the recent recognition of the benefits of PCSs, its implementation in patient care settings to achieve quality service remains a challenge. ${ }^{5,6,12,22-24}$ Knowing that one of the

Table 8 Ordinal logistic regression of patient needs for the "over-the-counter drugs and supplements" service

\begin{tabular}{|c|c|}
\hline Patient characteristics & $\begin{array}{l}\text { Unadjusted } \\
\text { OR }(95 \% \mathrm{Cl})\end{array}$ \\
\hline \multicolumn{2}{|l|}{ Age, years } \\
\hline$\geq 65$ & $0.59(0.36-0.98)$ \\
\hline \multicolumn{2}{|l|}{$<65$ (reference) } \\
\hline \multicolumn{2}{|l|}{ Education } \\
\hline College graduate or higher & $1.84(1.01-3.36)$ \\
\hline High school graduate & $1.65(0.88-3.11)$ \\
\hline \multicolumn{2}{|c|}{ Middle school graduate or less (reference) } \\
\hline \multicolumn{2}{|l|}{ Location of services } \\
\hline Seoul and its vicinity & $1.94(1.15-3.26)$ \\
\hline \multicolumn{2}{|l|}{ Local (reference) } \\
\hline \multicolumn{2}{|l|}{ Number of chronic diseases } \\
\hline$\geq 3$ & $0.65(0.33-1.28)$ \\
\hline 2 & $0.55(0.30-0.99)$ \\
\hline I (reference) & \\
\hline
\end{tabular}

major stakeholders of PCSs is the patient, patients' awareness and demands of the service should be reflected to develop such services.

In this study, we found that only one third of patients experienced at least one service, which showed that PCSs were not generally available or at least recognized among patients. But their satisfaction scores were high (ie, more than 4 points in all items); since the number of patients this applied to was low, more information is needed to generalize these results.

Moreover, we found that patients anticipated various PCSs throughout the treatment process. In a previous study, a telephone survey was conducted regarding patients' demand of the services by hospital pharmacists to help medication management. ${ }^{25}$ It revealed that most respondents, in addition to general health maintenance, expected to receive information about indication, dosage, directions to use, adverse reactions, and drug interactions of not only prescription medications including postdischarge medications but also nonprescription medications. Moreover, patients were unaware of the roles or activities as suggested by the fact that patients incorrectly assumed some of the pharmacy services were not linked with hospital pharmacies. Another study showed that $83.0 \%$ of patients who recalled meeting a pharmacist during admission were satisfied with the encounter; however, only $7.7 \%$ were related to pharmacy services. ${ }^{26}$

This finding can be similarly applied to our results. Paradoxically, patients' high satisfaction scores in this study may have been related to a low expectation of pharmacists. Like in other studies, our patients were not familiar with pharmacists' services or the range of pharmacists' activities. $^{26,27}$ The public should be educated on pharmacy services before developing PCSs so that patients' preferred needs can be reflected in the proposed details.

Patients with higher education levels showed high interest in "medication reconciliation", "medication changes", and "OTC drugs and supplements". This could reflect their intellectual curiosity and awareness of the potential benefits from the medications. Ironically, older patients and patients with more chronic diseases showed less demand for "medication changes" and "OTC drugs and supplements". We also found that patients who received services in Seoul tended to express a greater demand for PCSs, which might be due to frequent exposures in a medication-rich environment. ${ }^{27}$ This information can be applied to define the target group when developing PCSs and health care policies.

Direct delivery (ie, face-to-face) of PCSs was favored over indirect delivery methods (ie, email, text, or social 
networking). Patients may feel uncomfortable using indirect delivery methods; however, for the face-to-face method, the service time and place for private conversations should be considered to be standardized because local pharmacies in South Korea still focus on dispensing rather than facilitating PCSs for patients.

In our study, participants' willingness to pay was low (48\%) although we had $21 \%$ undecided. Some studies reported that $60-70 \%$ of the population was willing to pay for cognitive pharmacy services. ${ }^{28-31}$ Other studies showed that the better the financial condition of patients or the lower the out-of-pocket cost, the more willing people are to pay for pharmacists' services. ${ }^{29,31}$ Future studies should examine it considering patients' health insurance and financial condition.

\section{Study limitations}

First, the survey questionnaire was adapted based on a panel of pharmacy experts to avoid possible sources of errors and bias in the survey. The experts included pharmacy school faculty members, board-certified pharmacotherapy specialists from the American College of Clinical Pharmacy, clinical pharmacists, nurses, and physicians. Despite the fact that our survey was designed as a qualitative survey to discover the patients' acceptance status and perception of PCSs in South Korea, the content and construct validity and reliability were confirmed to be acceptable. Moreover, the format was introduced in accordance with the PCSs guidelines by the American Society of Health-System Pharmacists. ${ }^{32}$ Nevertheless, validation with more data is warranted in the near future. Second, patients were not aware of the previous services, thus causing difficulties in assessing the recall of PCSs. Third, the satisfaction with PCSs should be considered for the personnel factors and facility environment in the pharmacy, but these factors were not included in this study. In South Korea, technicians are not allowed to assist with dispensing work. Further research is needed on the various human and institutional factors for patients to be satisfied with their PCSs.

Despite the limitations, we believe that our findings offer valuable information to understand patients' recognition and need for PCSs. It also provides insight to overcome the lack of articulated standards for pharmacists' services and further initial data for developing a PCS model, especially in countries in the preliminary stages of PCSs development and standardization, including South Korea.

\section{Conclusion}

The overall satisfaction and expressed needs of the desired pharmacy services were high. Age, education, region, and number of chronic diseases affected patients' expressed needs for PCSs; however, our data emphasized that patients seemed to be unaware of the diversity of services offered by pharmacists. Future efforts should establish lists of the roles of pharmacists and develop standardized PCSs for target diseases.

\section{Acknowledgments}

We thank our colleagues of DrugTEAMTM (Drug Therapy Evaluation and Management) group and all interviewees for their priceless efforts.

This study was supported by a grant from the Korea Health Technology R\&D Project through the Korea Health Industry Development Institute (KHIDI), funded by the Ministry of Health \& Welfare, Republic of Korea (grant number: HI13C0731).

\section{Author contributions}

All authors contributed toward data analysis, drafting and critically revising the paper and agree to be accountable for all aspects of the work.

\section{Disclosure}

The authors report no conflicts of interest in this work.

\section{References}

1. World Health Organization. World Health Statistics 2016. Geneva: World Health Organization. Available from: http://who.int/gho/publications/world_health_statistics/2016/EN_WHS2016_TOC.pdf/ Accessed July 26, 2017

2. Ko SJ, Jung YH. Health-adjusted life expectancy in Korea. Issue Focus. 2014;247:1-8. Korean.

3. Korea National Statistical Office. 2015 Annual report on the cause of death statistics. Seoul, Korea: Korea National Statistical Office; 2015. Korean. Available from: http://kostat.go.kr/portal/korea/kor_nw/2/6/2/index.board?b mode $=$ download $\& b S e q=\& a S e q=356345 \&$ ord $=5$. Acessed July 29, 2017

4. Jarab AS, Alqudah SG, Khdour M, Shamssain M, Mukattash TL. Impact of pharmaceutical care on health outcomes in patients with COPD. Int J Clin Pharm. 2012;34(1):53-62.

5. Upadhyay DK, Mohamed Ibrahim MI, Mishra P, Alurkar VM. A nonclinical randomized controlled trial to assess the impact of pharmaceutical care intervention on satisfaction level of newly diagnosed diabetes mellitus patients in a tertiary care teaching hospital in Nepal. BMC Health Serv Res. 2015;15:57.

6. AbuRuz SM, Alrashdan Y, Jarab A, Jaber D, Alawwa IA. Evaluation of the impact of pharmaceutical care service on hospitalized patients with chronic kidney disease in Jordan. Int J Clin Pharm. 2013;35(5):780-789.

7. Bodenheimer T, Wagner EH, Grumbach K. Improving primary care for patients with chronic illness. JAMA. 2002;288(14):1775-1779.

8. Bodenheimer T, Chen E, Bennett HD. Confronting the growing burden of chronic disease: can the U.S. health care workforce do the job? Health Aff (Millwood). 2009;28(1):64-74.

9. Lee J, Sohn H, Shin H. Quality evaluation of medication counseling in Korean community pharmacies. Korean J Clin Pharm. 2009;19:131-142. 
10. Chang M, Cho E, Noh H, et al. Studies on the perception on clinical pharmaceutical care and clinical pharmaceutical sciences. Korean J Clin Pharm. 2014;24:169-182. Available From: http://www.ekjcp. org/journal/view.html?uid=94\&page $=\&$ sort $=\&$ scale $=10 \&$ all_k $=\&$ s_ $\mathrm{t}=$ Studies + on + the + perception $+\mathrm{on}+$ clinical + pharmaceutical + care + and + clinical + pharmaceutical + sciences $\&$ s_a $=\& s \_k=\& s \_v=\& s \_n=\& s p$ age $=\& p n=$ search \&year $=\& v m d=$ Full. Accessed June 05, 2016.

11. Cawthon C, Walia S, Osborn CY, Niesner KJ, Schnipper JL, Kripalani S. Improving care transitions: the patient perspective. J Health Commun. 2012;17(Suppl 3):312-324.

12. Surur AS, Teni FS, Girmay G, Moges E, Tesfa M, Abraha M. Satisfaction of clients with the services of an outpatient pharmacy at a university hospital in northwestern Ethiopia: a cross-sectional study. BMC Health Serv Res. 2015;15:229.

13. Yang S, Kim D, Choi HJ, Chang MJ. A comparison of patients' and pharmacists' satisfaction with medication counseling provided by community pharmacies: a cross-sectional survey. BMC Health Serv Res. 2016;16:131.

14. Lee S, Godwin OP, Kim K, Lee E. Predictive factors of patient satisfaction with pharmacy services in South Korea: a cross-sectional study of national level data. PLoS One. 2015;10(11):e0142269.

15. Sohn HS, Kim HJ, Park HK, Han N, Oh JM, Ji E. Pharmaceutical care services of community pharmacies in Korea through the review of literature. Korean J Clin Pharm. 2015;25(1):18-26.

16. Park HK, Choi SM, Kim SH, et al. Introducing a health promoting pharmacy model: Safe Pharmacy Program of Seoul. J Health Technol Assess. 2016;4(1):1-5. Available from: http://www.kahta.or.kr/eboard/data/ academy/72\$2\$4-1-6-\%EA\%B0\%95\%EC\%9D\%80\%EC\%A0\%95. pdf. Accessed January 16, 2017.

17. Kang EJ, Park HK. Success factors for the smoking cessation service of the safe pharmacy. Korean J Clin Pharm. 2017;27(1):38-43. Available from: http://www.ekjcp.org/journal/view.html?uid=595\&page=\&sort=\&scale= $10 \& a l l \_\mathrm{k}=\& \mathrm{~s} \_\mathrm{t}=\& \mathrm{~s} \_\mathrm{a}=\% \mathrm{EA} \% \mathrm{~B} 0 \% 95 \% \mathrm{EC} \% 9 \mathrm{D} \% 80 \% \mathrm{EC} \% \mathrm{~A} 0 \% 95 \& \mathrm{~s}$ _ $\mathrm{k}=\& \mathrm{~s} \_\mathrm{v}=\& \mathrm{~s} \_\mathrm{n}=\&$ spage $=\& \mathrm{pn}=$ search $\&$ year $=\& \mathrm{vmd}=$ Full. Accessed on December 11, 2016.

18. pharm21.com. Kim GR. [Development of smart pharmacy management model]. Pharmacy Newsletter, April 25, 2013. Available from: http:// www.pharm21.com/news/articleView.html?idxno=77641. Accessed July 18, 2017. Korean.

19. Park SJ, Shin HT. The major barriers to provision of pharmaceutical care service in compliance with internationally recognized good pharmacy practice standards in community pharmacies in Korea: a questionnaire survey. Korean J Clin Pharm. 2014;24(4):272-281. Available from: http:/ www.ekjcp.org/journal/view.html?uid $=108 \&$ page $=\&$ sort $=\&$ scale $=10 \&$ all_k=\&s_t=\&s_a=\%EC $\% 8 B \% A 0 \% E D \% 98 \% 84 \% E D \% 83 \% 9 D \& s \_$ $\mathrm{k}=\& \mathrm{~s} \_\mathrm{v}=\& \mathrm{~s} \_\mathrm{n}=\&$ spage $=\& \mathrm{pn}=$ search $\&$ year $=\& \mathrm{vmd}=$ Full. Accessed July 23, 2016.
20. Sun WY, Tong L, Li DX, et al. Selection of reference standard during method development using the analytical hierarchy process. $J$ Pharm Biomed Anal. 2015;107:280-289.

21. Lee IH, Rhie SJ, Je NK, et al. Perceived needs of pharmaceutical care services among healthcare professionals in South Korea: a qualitative study. Int J Clin Pharm. 2016;38(5):1219-1229.

22. van Mil JW, Schulz M, Tromp TF. Pharmaceutical care, European developments in concepts, implementation, teaching, and research: a review. Pharm World Sci. 2004;26(6):303-311.

23. Roughead EE, Semple SJ, Vitry AI. Pharmaceutical care services: a systematic review of published studies, 1990 to 2003, examining effectiveness in improving patient outcomes. Int J Pharm Pract. 2005; 13(1):53-70.

24. Wang T, Benedict N, Olsen KM, et al. Effect of critical care pharmacist's intervention on medication errors: A systematic review and meta-analysis of observational studies. J Crit Care. 2015;30(5): 1101-1106.

25. Gould O, Buckley P, Doucette D. What patients want preferences regarding hospital pharmacy services. Can J Hosp Pharm. 2013;66(3): 177-183.

26. Slack LR, Ing L. Prevalence and satisfaction of discharged patients who recall interacting with a pharmacist during a hospital stay. Can J Hosp Pharm. 2009;62(3):204-208.

27. Oh YH. Improvement ways for health care delivery system. Health and Welfare Policy Forum. 2012;189:50-67. Available from: https://www. kihasa.re.kr/common/filedown.do?seq=31984. Accessed February 10, 2017.

28. Schuh MJ, Droege M. Cognitive services provided by pharmacists: is the public willing to pay for them? Consult Pharm. 2008;23(3):223-230.

29. Larson RA. Patients' willingness to pay for pharmaceutical care. J Am Pharm Assoc (Wash). 2000;40(5):618-624.

30. Shafie AA, Hassali MA. Willingness to pay for a pharmacist's dispensing service: a cross-sectional pilot study in the state of Penang, Malaysia. Pharm Pract (Granada). 2010;8(2):116-121.

31. Tsao NW, Khakban A, Gastonguay L, Li K, Lynd LD, Marra CA. Perceptions of British Columbia residents and their willingness to pay for medication management services provided by pharmacists. Can Pharm J (Ott). 2015;148(5):263-273.

32. No authors listed. ASHP guidelines on a standardized method for pharmaceutical care. American Society of Health-System Pharmacists. Am J Health Syst Pharm. 1996;53(14):1713-1716.
Patient Preference and Adherence

\section{Publish your work in this journal}

Patient Preference and Adherence is an international, peer-reviewed, open access journal that focuses on the growing importance of patient preference and adherence throughout the therapeutic continuum. Patient satisfaction, acceptability, quality of life, compliance, persistence and their role in developing new therapeutic modalities and compounds to optimize

\section{Dovepress}

clinical outcomes for existing disease states are major areas of interest for the journal. This journal has been accepted for indexing on PubMed Central. The manuscript management system is completely online and includes a very quick and fair peer-review system, which is all easy to use. Visit http://www dovepress.com/testimonials.php to read real quotes from published authors. 